thread in the forceps tie slides over it a little more easily than with the other. The increased control of the small needle, and the shortened distance between the fingers and the jaws make corneal suturing much easier, and the flattened jaws never fail to grasp the finest thread, thus improving the instrument for cataract extraction and keratoplasty, while retaining its advantages for other ophthalmic operations.

\title{
REFERENCE
}

FOSTER, J. (1938). British Journal of Ophthalmology, 15, 430.

Brit. J. Ophthal. (1956) 40, 61.

\section{SHADE ATTACHED TO SPECTACLE FRAME TO PROTECT FROM GLARE IN EARLY OR PREMATURE CATARACT*}

BY

\section{H. NEAME \\ London}

THE eye-shade is attached to the spectacle-frame for patients with early or immature cataract. It is well known that such patients often see much more clearly in sunlight and in artificial light if the eyes are shaded from glare by holding a hand against the forehead immediately above the eyes. The eye-shade (Figure) must be made for the individual so as to fit accurately the curve of the forehead.

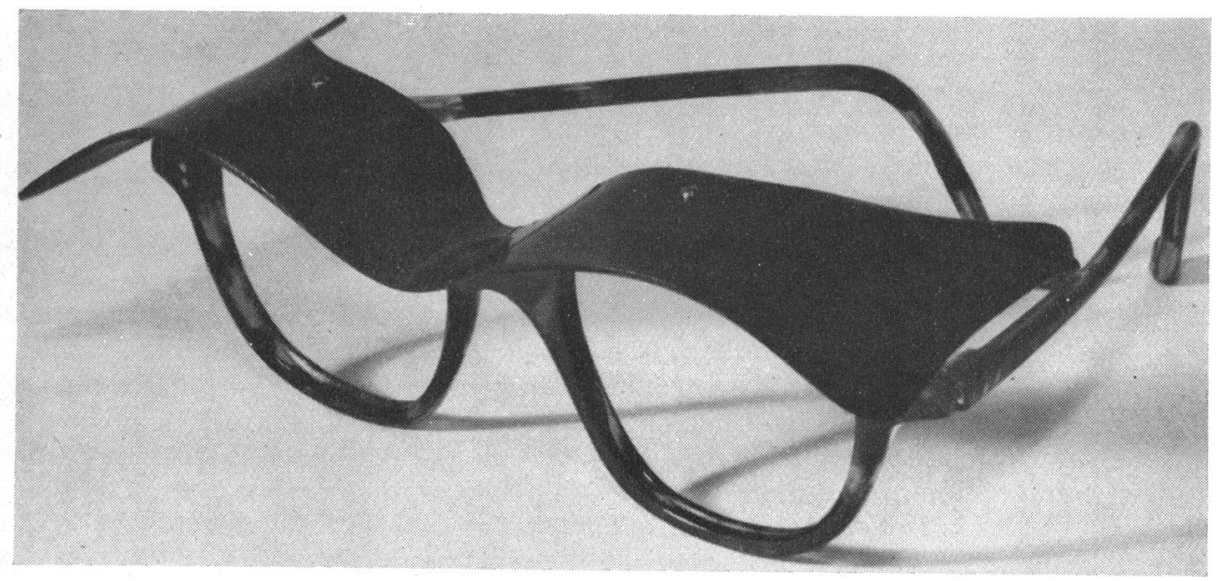

The shade may be used with distance, bifocal, or reading glasses, and has been of some benefit even when the visual acuity was as good as 6/12. 